\title{
CONFLITOS DE LEIS TRABALHISTAS NO ESPAÇO E A CIRCULAÇÃO DE TRABALHADORES
}

\author{
Sérgio Pinto Martins \\ Professor Associado do Departamento de Direito do Trabalho \\ da Faculdade de Direito da Universidade de São Paulo
}

\section{Resumo:}

São vários os elementos de conexão que na prática são utilizados: lei do local da prestação dos serviços, lei do local da contratação, lei da sede da empresa, lugar da celebração do contrato, lugar de onde são emitidas as ordens de serviço, moeda utilizada para o pagamento do salário, língua na qual foi redigido o contrato, nacionalidade comum, norma mais favorável, autonomia da vontade. Em certos casos, não se aplica apenas um dos elementos de conexão, mas a combinação de vários deles, com critérios flexíveis. A observância da autonomia da vontade nem sempre pode ser utilizada, pois o empregador pode impor ao empregado a norma a ser aplicada, daí a necessidade de proteção do trabalhador. Entretanto, a aplicação da lei mais favorável é que irá trazer maiores vantagens ao empregado, fazendo, muitas vezes, a verdadeira Justiça.

\begin{abstract}
:
There are several points of contact that are used: lex loci laboris, lex loci contractus, law of the head office's organization, local of celebration of the contract, local where the orders came from, money wage's payment, language of the contract, nationality, most favorable law, party autonomy. In some cases, do not use only one point of contact, but a combination of several them, with flexible criterions. Cannot be used in al cases the criterion of the party autonomy because employer can impose to the employee the norm that will be followed. So the employee needs protection. However, the application of the most favorable law can bring to the employee the best advantages, doing the truely justice.
\end{abstract}

Unitermos: conflito; lei trabalhista; espaço circulação. 
I. Introdução

No presente trabalho será feito um estudo sobre os conflitos das leis trabalhistas no espaço. Ao final, será analisada a circulação dos trabalhadores e a aplicação das leis trabalhistas.

Conflito de leis no espaço implica a existência de mais de uma norma a ser aplicável a um mesmo caso concreto. Há necessidade de se resolver a antinomia entre as normas, de forma a solucionar o conflito.

\section{Elementos de conexão}

No Brasil utiliza-se a denominação elementos de conexão. Na Alemanha, usa-se a expressão "Anknüpfungspunkt", que tem o significado de vínculo ativo. Na Itália, "punto de collegamento" "momenti di collegamento" "criterio di collegamento" Em França, "point de rattachement" ou "circonstances" $\mathrm{Na}$ Espanha, "circunstancia de conexión" ou "puntos de conexión" $\mathrm{Na}$ Inglaterra, "localizer". Em outros países de língua inglesa também são utilizadas as expressões: "connecting factors" ou "points of contact"

Haroldo Valladão menciona que os elementos de conexão "são as diretrizes, as chaves, as cabeças-de-ponte para a solução dos conflitos de leis, em linguagem atual são os mísseis que põem em órbita a regra de DIP" 1 Visam os elementos de conexão à aplicabilidade da lei mais justa.

Define Giuseppe Barile elemento de conexão como a circunstância da relação jurídica à qual a norma de Direito Internacional Privado atribui relevância na solução de conflito de leis. ${ }^{2}$ Irineu Strenger esclarece que elemento de conexão é "o fator de vinculação, de ligação a determinado sistema jurídico, porque é através dele que sabemos qual o direito aplicável. É o vínculo que relaciona um fato qualquer a determinado sistema jurídico. ${ }^{3} \mathrm{Em}$ outra obra, o autor explica que "elementos de conexão são expressões legais de conteúdo variável, de efeito

1. Valladão, Haroldo. Direito Internacional Privado, Rio de Janeiro, Livraria Freitas Bastos, 1971, v. I, p. 266.

2. Barile, Giuseppe. Collegamento - verbete em Enciclopédia del Diritto, Varese, Giuffrè, 1960, VII, p. 351 . 386

3. Strenger, Irineu. Curso de Direito Internacional Privado, Rio de Janeiro, Forense, 1978, p. 
indicativo, capazes de permitir a determinação do direito que deve tutelar a relação jurídica em questão". ${ }^{4}$

Os elementos de conexão serão a chave para a resolução do conflito de leis no espaço. Irão indicar o Direito que irá ser aplicável ao caso em tela.

São elementos de conexão: a. nacionalidade (lex patriae), em que se verifica a pessoalidade, como em matéria de divórcio; b. autonomia de vontade; c. lei onde estiver situado o bem (lex rei sitae). Os bens regem-se pela lei do local onde estiverem situados; d. lei do local do ato (locus regit actum); e. lei do local da execução (lex loci executionis); f. lei do foro (lex fori).

Poderão os elementos de conexão variar de acordo com cada ordenamento jurídico. Não há, muitas vezes, uma solução uniforme e universal para resolver o conflito de leis no espaço.

III. Conflitos de leis trabalhistas no espaço

Há vários elementos de conexão que podem ser observados para a solução do conflito trabalhista no espaço. Entre eles podem ser destacados: lei do local da prestação de serviços, lei do local da contratação, nacionalidade, norma mais favorável, etc.

O critério mais aceito pelas legislações é o da lei da execução do contrato de trabalho (lex loci laboris ou lex loci executionis). Importa, segundo esse critério, onde o empregado efetivamente presta serviços, sendo-lhe aplicável a respectiva lei do local.

A antiga Lei de Introdução ao Código Civil, revogada em 1942, previa no parágrafo único do art. 13 que "sempre se regerão pela lei brasileira: II- as obrigações contraídas entre brasileiros, em país estrangeiro" Clóvis Bevilaqua criticava a referida norma dizendo que a imposição da lei nacional, sem espaço para a adoção da lex loci contractus, não "se harmoniza com a pureza da doutrina do direito internacional (...) em matéria de contratos. 5

À primeira vista, dever-se-ia aplicar o art. $7^{\circ}$ da Lei de Introdução ao Código Civil, dizendo que "a lei do país em que for domiciliada a pessoa determina

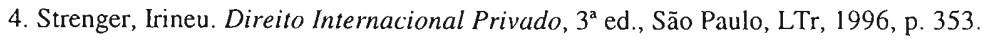

5. Bevilaqua, Clovis. Código Civil, São Paulo, Francisco Alves, 1944, v. I, p. 145. Tinha o mesmo entendimento J. M. de Carvalho Santos (Código Civil brasileiro interpretado, Rio de Janeiro, Freitas Bastos, 1937, v. I, p. 165). 
as regras sobre o começo e o fim da personalidade, o nome, a capacidade e os direitos de família" Entretanto, essa regra não se aplica ao contrato de trabalho. $\mathrm{O}$ art. $9^{\circ}$ da mesma norma esclarece que "para qualificar e reger as obrigações, aplicar-se-á a lei do país em que se constituírem" e "destinando-se a obrigação a ser executada no Brasil e dependendo de forma essencial, será esta observada, admitidas as peculiaridades da lei estrangeira, quanto aos requisitos extrínsecos do ato. A obrigação resultante do contrato reputa-se constituída no lugar em que residir o proponente"

Esclarece o art. 198 do Código de Bustamante que "também é territorial a legislação sobre acidentes do trabalho e proteção social do trabalhador" O contrato de trabalho é regido pela lei do local da prestação do serviço. Não se observa, portanto, a vontade das partes na celebração do contrato. Foi o Código de Bustamante ratificado pelo Brasil e promulgado pelo Decreto $\mathrm{n}$. 18.871, de 13 de agosto de 1929. Importante lembrar que o Código de Bustamante só se aplica nos casos em que haja interesses de nacionais dos Estados Americanos que o ratificaram, não sendo observado se houver interessados nacionais de um mesmo Estado. Ensina Octavio Bueno Magano que "a regra básica é, portanto, a da 'lex loci laboris', cuja justificativa repousa na idéia de que trabalhadores de um mesmo território não devem estar sujeitos a regimes jurídicos diferentes" 6 Seria, assim, aplicável a lei do local da prestação dos serviços tanto no curso do contrato de trabalho, quanto em razão do término da relação laboral. Normalmente se utiliza a "lex loci laboris" entre vários elementos de conexão, porque o Estado de origem não iria permitir que seus súditos viessem a se submeter a condições de trabalho inferiores ao padrão mínimo por ele determinado. ${ }^{7}$ Com isso, há igualdade de tratamento em relação aos empregados que prestam serviços numa mesma localidade. Na maioria das vezes, as prestações recíprocas entre empregado e empregador, envolvendo direitos e obrigações, incluem o local da prestação dos serviços.

A atual Lei de Introdução ao Código Civil não teria revogado o art. 198 do Código de Bustamante, pois a lei geral não-revoga a especial $\left(\S 2^{\circ}\right.$, do art. $2^{\circ}$ da Lei de Introdução ao Código Civil). Assim, prevalece a regra contida no art. 198

6. Magano, Octavio Bueno. Conflito de leis trabalhistas no espaço (lineamentos), in LTr 51-8/917

7. Rodiére, Pierre. Conflits de lois en Droit du Travail: étude comparative, Paris, Droit Social, $\mathrm{n}$.

2, Février, 1986, p. 125. 
do Código de Bustamante para efeito da solução de conflitos de leis no espaço, aplicando-se a lei do local da prestação dos serviços.

A doutrina entende que deve ser aplicada a lei da execução do contrato de trabalho para a solução dos conflitos de lei no espaço. Gilda Russomano afirma que a solução dos conflitos entre leis aplicáveis ao contrato de trabalho é observada pela aplicação da norma em vigor no lugar da execução do trabalho, pois o lugar de execução surge como elemento relevante. ${ }^{8}$ Haroldo Valladão informa que, entre os outros critérios a serem utilizados como elementos de conexão, prevalece o da lei do lugar da execução como regra geral, estando superados os demais critérios. ${ }^{9}$ Arnaldo Süssekind conclui que o elemento de conexão a ser aplicado em matéria trabalhista é o da territorialidade, de acordo com o Código de Bustamante. ${ }^{10}$

Mesmo o Tribunal Regional Federal da $2^{\mathbf{a}}$ Região entendeu que a lei aplicável é a do local da prestação dos serviços:

"Trabalhista contrato celebrado no Exterior legislação aplicável. I- Contrato de Trabalho celebrado no Exterior, entre brasileira e o Escritório do Instituto Brasileiro do Café em Nova York dentro da legislação norte-americana. Aplicação do princípio Lex Loci Executionis. II- Recurso Ordinário a que se nega provimento" 11

Ressalte-se que não é apenas a legislação trabalhista que é territorial. $\mathrm{O}$ art. $5^{\circ}$ do Código Penal também mostra a territorialidade da aplicação da lei brasileira, sem prejuízo de convenções, tratados e regras de Direito Internacional, ao crime cometido no território nacional.

8. Russomano, Gilda. Direito Internacional do Trabalho, Rio de Janeiro, Forense, 1979, p. 184.

9. Valladão, Haroldo. Direito Internacional Privado, Rio de Janeiro, Livr. Freitas Bastos, s.d.p., v. III, p. 95. p. 31 .

10. Süssekind, Arnaldo. Conflitos de leis do trabalho, Rio de Janeiro, Livr. Freitas Bastos, 1979 ,

11. TRF 2a R, 1a T, RO 0114-89.02131912-3, Rel. des. Fed. Ney Fonseca, j. 28.02.96, DJU 2 16.04 .96$, p. 24.270 . 
A Convenção de Roma, de 19 de junho de 1980, também explicita que o contrato de trabalho regula-se: a) pela lei do país no qual o trabalhador, em execução de seu contrato, desenvolva habitualmente o seu trabalho"

A jurisprudência trabalhista firmou-se no sentido da aplicação da lei do local da execução do contrato de trabalho, surgindo o Enunciado n. 207 do Tribunal Superior do Trabalho (TST). O verbete tem fundamento no Código de Bustamante (art. 198). Sua redação é a seguinte: "a relação jurídica trabalhista é regida pelas leis vigentes no país da prestação de serviço e não por aquelas do local da contratação"

Um dos acórdãos que levaram à adoção do Enunciado n. 207 do TST tem, em parte, a justificativa de que "em sua grande maioria, as normas relativas ao trabalho são imperativas, aspecto a relegar a plano secundário a vontade das partes. A autonomia pertinente a esta última cede lugar à conveniência de o próprio Estado disciplinar a solução dos conflitos sociais, atento às peculiaridades reinantes e aos anseios da sociedade.... ${ }^{12}$ Em outro acórdão o TST decidiu:

"1 - O princípio de que a lei do local da celebração rege o contrato não é absoluto, pois cede ante ao princípio da regência pela lei do local de execução do contrato, quando em questão está a soberania nacional, a ordem pública e os bons costumes (art. $9^{\circ}$ e 17 da Lei de Introdução ao Código Civil brasileiro). 2. As normas de proteção ao trabalhador são cogentes, atraindo limitação ao princípio da 'lex loci actum'. 3- Os direitos e obrigações trabalhistas são regidos pela lei do local de prestação de serviços ('Lex loci executionis'), por força dos arts. 17 da Lei de Introdução ao Código Civil e 198 do Código de Bustamante, verdadeiro Código de Direito Internacional Privado, vigente no Brasil, porque ratificado pelo Decreto n. 18.874, de 13 de agosto de 1929. 4-Aplica-se a 'lex loci executionis', em atenção ao princípio da territorialidade (Código de Bustamante), atraído pela natureza cogente das normas trabalhistas (Süssekind), que são de ordem pública internacional (Délio Maranhão). Estes aspectos afastam a possibilidade de derrogação pela vontade das partes (Deveali), e realçam a necessidade de tratamento idêntico dos empregadores que ombreiam (Durand, Jaussaud e Gilda Russomano), e do fato de as

12. TST $1^{\text {a }}$ T, RR 2.562/83, Rel. min. Marco Aurélio Mendes de Farias Mello, in João de Lima Teixeira Filho, Repertório de Jurisprudência Trabalhista, $4^{\circ}$ v., Freitas Bastos, 1986, p. 653, n. 3.173. 
prestações que entre si devem as partes estarem ligadas, geograficamente, ao lugar da execução do contrato (Manoel Alonso Olea)" 13

A nossa jurisprudência tomou por base a orientação de Henri Batiffol, no sentido de que "a jurisprudência foi levada a decidir que a evidente intenção do legislador era a aplicação de seus preceitos a todo contrato de trabalho executado em seu território. As idéias de proteção da pessoa humana que inspiram esta legislação exigem que ela seja, em princípio, imposta em benefício de qualquer indivíduo que trabalhe no país" 14

O TST recentemente aplicou a lex loci executionis:

"Os direitos e obrigações trabalhistas são regidos pela lei do local em que são prestados os serviços - lex loci executionis - face ao contido nos arts. 17, da Lei de Introdução ao Código Civil, e 198 do Código de Bustamante, verdadeiro Código de Direito Internacional Privado, vigente no Brasil, porque ratificado pelo Decreto $n .18 .871$, de 13 de agosto de 1929... ${ }^{15}$

Não-trata, porém, o $\$ 2^{\circ}$ do art. 651 da CLT de conflitos de leis trabalhistas no espaço, apenas fixa a competência da Justiça do Trabalho brasileira para resolver os conflitos entre empregados brasileiros contratados para trabalhar no Exterior, salvo se houver tratado internacional dispondo em sentido contrário. $\mathrm{Na}$ jurisprudência brasileira, a regra não seria a aplicação da legislação brasileira caso o empregado trabalhe no Exterior, mas sim a lei do local da prestação dos serviços, segundo a orientação do Enunciado n. 207 do TST.

É de se ressaltar, contudo, que o Enunciado n. 207 do TST nãoresolve todos os problemas jurídicos existentes na aplicação da lex loci laboris. O exemplo seria o caso de um empregado brasileiro que tivesse trabalhado dois anos no Brasil, posteriormente passou seis meses no Uruguai, dois meses na Itália, cinco

13. TST, Pleno, RR 7.238/84, Rel. min. Marco Aurélio, DJU 27.3.87, p. 5.243.

14. Batiffol, Henri. Les conflits de lois en matière de contrats, Sirey, Paris, 1938, p. 262.

15. TST- $4^{\mathrm{a}}$ T, Proc. RR n. 179.910/95.8, Ac. n. 7.302/97, j. 20.9.97, Rel. min. Milton de Moura França, in Trabalho \& Doutrina, São Paulo, Saraiva, n. 15, p. 131. 
meses na Inglaterra e por fim foi dispensado na França, onde trabalhou um ano. Qual a lei trabalhista a ser aplicada a tal trabalhador? Segundo a orientação do Enunciado n. 207 do TST, seria aplicável ao trabalhador cada lei do respectivo país em que houve a prestação dos serviços, isto é, nos dois primeiros anos seria aplicada a lei brasileira, nos seis meses seguintes a lei uruguaia, nos dois meses seguintes a lei italiana, nos cinco meses subseqüentes a lei inglesa e no último ano a lei francesa. Isso porque a maioria dos países adota o entendimento de que se deve aplicar a lei do local da prestação de serviços, em se tratando de questões trabalhistas. A Convenção de Roma, de 1980, estabelece, porém, que o contrato de trabalho regulase alternativamente "pela lei do país em que se situa a sede da empresa responsável pela contratação do trabalhador, quando este não desenvolva habitualmente o seu trabalho em determinado país"

Admite a doutrina que se o trabalhador domiciliado no país é contratado por empresa nacional, visando à prestação de serviços no Exterior, devem ser asseguradas as garantias mínimas decorrentes da lei do país das partes contratantes, sem prejuízo da aplicação das condições de trabalho mais favoráveis do país da prestação de serviço. ${ }^{16}$

Informa Felice Morgenstern que "na jurisprudência européia os trabalhadores, satisfeitos de trabalhar sob as condições de um contrato de trabalho regido pela lei norte-americana, buscam a proteção de um Direito europeu quando da cessação do contrato de trabalho." ${ }^{17}$ Isso se justifica porque a legislação americana não traz proteção ao trabalhador dispensado. Seria mais vantajosa, por exemplo, a aplicação da lei brasileira do que a americana na rescisão do contrato de trabalho, pois há direito a aviso prévio, férias proporcionais, $13^{\circ}$ salário proporcional, indenização de $40 \%$ sobre os depósitos do FGTS, liberação dos depósitos fundiários e seguro-desemprego.

$\mathrm{Na}$ Argentina, o art. $3^{\circ}$ da Lei do Contrato de Trabalho explicita que "esta lei regerá a validade, direitos e obrigações das partes, seja se o contrato de trabalho tiver se celebrado no país ou fora dele, enquanto se execute em seu território, qualquer que seja a nacionalidade das partes" Afirma Eduardo L. Fermé que "se o direito estrangeiro escolhido for menos benéfico para o trabalhador, a

16. Rodière, Pierre. Conflits de lois en Droit du Travail: étude comparative, in Droit Social, Paris, 1986, février, n. 2, p. 126.

17. Morgenstern, Felice. Les conflits de lois en droit du travail, Genebra, BIT, 1986, p. 2. 
modificação realizada não terá eliminado do Direito Internacional Privado argentino o critério da aplicação do direito mais favorável ao trabalhador quando este direito for o argentino" 18

$\mathrm{O}$ art. $2^{\circ}$ do Código Substantivo do Trabalho tem dispositivo semelhante ao argentino, esclarecendo que "o presente Código vige em todo território da República, para todos os seus habitantes, sem consideração de sua nacionalidade"

Determina o art. 43 do Regulamento da Ley del Trabajo da Venezuela que os contratos de trabalho celebrados por trabalhadores venezuelanos para prestação de serviços fora do país serão regidos pelas disposições da Lei do Trabalho venezuelana que favoreçam os trabalhadores. É a aplicação da norma mais favorável ao trabalhador e não da lei da contratação, pois a lei venezuelana pode não ser melhor do que a estrangeira.

Na Espanha, o Estatuto dos Trabalhadores dispõe que 'a legislação do trabalho espanhola será aplicada no trabalho prestado pelos trabalhadores contratados na Espanha a serviço de empresas espanholas no Exterior, sem prejuízo das normas de ordem pública aplicáveis no lugar do trabalho" (art. $1^{\circ}$, alínea $4^{\text {a }}$ ). Leciona Manuel Alonso Olea que "a lei espanhola atua como condição mínima, o que significa que as partes podem optar, se mais favorável para o trabalhador, pela lei do lugar da execução" 19

Gérard Lyon-Caen menciona que na Comunidade Econômica Européia é aplicável o princípio da lei mais favorável, como forma de solucionar os conflitos de leis no espaço em matéria trabalhista. ${ }^{20}$

Permite o art. 44 da Lei Federal austríaca, de 15 de junho de 1978, a escolha, pelas partes, da lei reguladora da relação jurídica. Para a validade de tal orientação é preciso que a escolha seja expressa. $O \S 3^{\circ}$ da referida norma estabelece que a escolha será desconsiderada quando, ainda que expressa, seus efeitos forem prejudiciais ao trabalhador.

18. Fermé, Eduardo L. Derecho Internacional Privado del Trabajo, in Tratado de Derecho del Trabajo, director Antonio Vásquez Vialard, Buenos Aires, Editorial Astrea. 1982, t. 2., p. 894.

19. Alonso Olea, Manuel. El estatuto de los trabajadores texto y comentario breve, Madrid, Civitas, 1980, p. 21.

20. Lyon-Caen, Gérard. Droit social international et européen, $3^{2}$ ed., Paris, Dalloz, 1974, p. 97. 
Mario Deveali também admite que deve "ser adotado o princípio da norma mais favorável para dirimir o conflito entre a lei nacional, a lex contractus, a lex executionis, $e$ a lex solutionis" 21

No Brasil, a Lei n. 7.064, de 6 de dezembro de 1982, regulamentada pelo Decreto n. 89.339, de 31 de janeiro de 1984, traz orientação diferente da contida no Enunciado n. 207 do TST. Essa norma aplica-se apenas aos trabalhadores contratados no Brasil, ou transferidos por empresas prestadoras de serviços de engenharia, inclusive consultoria, projetos e obras, montagens, gerenciamento e congêneres, para prestar serviços no Exterior (art. $1^{\circ}$ ). Não dispõe a referida norma que o empregado deve ser brasileiro, o que dá a entender que pode ser qualquer trabalhador, inclusive o estrangeiro, desde que seja contratado no Brasil. $\mathrm{O}$ art. $3^{\circ}$ do citado mandamento legal estabelece que "a empresa responsável pelo contrato de trabalho do empregado transferido assegurar-lhe-á, independentemente da observância da legislação do local da execução dos serviços: II- a aplicação da legislação brasileira de proteção ao trabalho, naquilo que não for incompatível com o disposto nesta Lei, quando mais favorável do que a legislação territorial, no conjunto de normas e em relação a cada matéria" É certo que nossa legislação ou a estrangeira pode conter regras menos favoráveis, sendo que a última não possui o FGTS, o PIS, etc. Assim, dever-se-ia verificar cada instituto para constatar o mais benéfico ao empregado, isto é, cada conjunto de regras relativas à mesma matéria, de modo a observar a disposição legal que se refere "ao conjunto de normas e em relação a cada matéria" A legislação aplicável ao empregado será a legislação brasileira de proteção ao trabalho, naquilo que não for incompatível com o disposto na Lei n. 7.064, quando mais favorável do que a legislação do local da prestação dos serviços, no conjunto de normas e em relação a cada matéria (art. $3^{\circ}$, II, da Lei n. 7.064). Assim, podemos dizer que a regra é a aplicação da norma mais benéfica no seu conjunto e em relação a cada matéria. Em princípio, se o trabalhador brasileiro é contratado em nosso país para trabalhar para empresa estrangeira no Exterior seria aplicável a lex loci executionis. Existem autores que preconizam que as regras da Lei n. 7.064 sejam estendidas a qualquer empregado que preste serviços no Exterior ou em mais de um lugar no estrangeiro.

21. Deveali, Mario L. El Derecho del Trabajo en su aplicación y sus tendencias, I, Buenos Aires, Editorial Astrea, 1983, p. 130. 
Há sustentação no sentido de que se houver várias leis trabalhistas a aplicar, que se aplique a mais favorável, mesmo que a empresa não seja de engenharia. Gilda Russomano afirma que "dever-se-ia considerar aplicável à relação jurídica, sobre a qual controvertem duas ou mais de duas leis oriundas de soberanias distintas, aquela que maiores benefícios outorgar ao trabalhador. $22 \mathrm{Um}$ Estado não-permitiria que ao seu trabalhador fossem aplicadas condições de trabalho inferiores ao deste local em relação ao trabalho prestado no estrangeiro.

Octavio Bueno Magano admite a aplicação analógica das disposições da Lei n. 7.064/82 "em qualquer hipótese em que trabalhadores domiciliados no Brasil sejam mandados para o Exterior ou em virtude de transferência ou decorrência de contrato adrede celebrado para o apontado efeito" ${ }^{23}$ Segundo esse entendimento, não seria possível deixar de aplicar aos trabalhadores domiciliados no Brasil a lei brasileira, que seria mais favorável do que a estrangeira, ainda que a prestação de serviços estivesse se desenvolvendo no Exterior.

A aplicação da norma mais favorável objetiva evitar que o empregador imponha ao empregado no contrato de trabalho norma menos vantajosa, que seria um abuso na forma de contratação.

Felice Morgenstern mostra a orientação jurisprudencial na Itália, indicando que, em decisão de 6 de setembro de 1980, a Corte de Cassação italiana decidiu que se a lei aplicável a um trabalho executado na Itália for menos favorável para o trabalhador do que a lei italiana é esta que deve ser aplicada. Em decisão de 9 de novembro de 1981, a Corte de Cassação aplicou a lei italiana a um contrato celebrado entre nacionais italianos, que deveria ser executado na Argentina e para o qual as partes haviam escolhido a lei argentina a ser observada, em razão de que a lei italiana era mais favorável para o trabalhador. ${ }^{24}$

Em certos casos surge o problema de se saber qual a lei mais favorável e como aplicá-la: se no seu conjunto ou instituto por instituto. Deveria ser aplicada a norma que no seu conjunto representasse mais vantagens ao empregado e não instituto por instituto, de forma a pinçar cada um deles. Haroldo Valladão bem

22. Russomano, Gilda. Op. cit., p. 207.

23. Magano, Octavio Bueno. Manual de Direito do Trabalho Parte Geral, São Paulo, LTr, 1991, p. 130.

24. Morgenstern, Felice. Op. cit., pp. $55 / 6$ (nota 42). 
esclarece sobre como identificar a norma mais favorável: "basta perguntar ao empregado ou ao empregador e eles o dirão logo" 25

A norma coletiva brasileira não pode, porém, ser aplicada no estrangeiro, pois a empresa estrangeira não foi parte na relação, tendo observância apenas no território brasileiro. É uma norma de aplicação territorial, circunscrita ao local em que está sendo prestado o serviço e não no estrangeiro. Ressalte-se que os sindicatos têm base territorial e é nessa base que a norma coletiva é aplicada.

IV. Tripulantes de embarcações e aeronaves

Em relação a tripulantes de embarcações e aeronaves a orientação geral é a utilização da lei da bandeira do navio ou da aeronave. A lei da bandeira do navio não será o critério absoluto a ser observado, pois a relação de emprego se estabelece entre a empresa que explora a embarcação ou aeronave e o empregadotripulante e não entre este e o proprietário do navio ou aeronave.

O pavilhão também poderia ser mudado constantemente. Nesse sentido, seria observada a lei do pavilhão definitivo do navio ou aeronave. Se a transferência do navio ou aeronave é provisória, aplica-se a lei anterior. Se é definitiva, aplica-se a lei do pavilhão novo.

Seria possível navegar sob bandeira falsa, para aplicar a lei de determinado país, visando fraudar os direitos do trabalhador e pagar valores inferiores aos devidos. Poderia também o navio ser matriculado ou inscrito em país que tenha deficiente legislação trabalhista, sendo desfavorável aos empregados. Nesses casos, admite-se a aplicação da lex loci contractus e a observância de norma de ordem pública sobre a lei do pavilhão. ${ }^{26}$

V. Acidente do trabalho

O art. $2^{\circ}$ da Convenção n. 19 da OIT, aprovada pelo Decreto Legislativo n. 24, de 29 de maio de 1956, e promulgada pelo Decreto n. 41.721, de

25. Valladão, Haroldo. Direito Internacional Privado, Rio de Janeiro, Freitas Bastos, s.d.p., v. III, p. 100 .

26. Nesse sentido é o entendimento de Atilio Malvagni - Derecho laboral de la navegación, Buenos Aires, 1949, p. 390. O Tratado sobre Navegação Comercial de Montevidéu, de 1940, tem a mesma previsão nos arts. 20 e 21. 
25 de junho de 1957, prevê que para a indenização por acidente do trabalho sobrevindo a trabalhadores ocupados temporária ou intermitentemente no território de um membro, por conta de empresa situada em território de outro membro, poderá ser prevista a aplicação da legislação deste último, por acordo especial entre os membros interessados. A regra é facultativa, pois pode não haver previsão para aplicação de determinada lei. Lembre-se, ainda, que o artigo citado menciona a sua aplicação em relação a trabalhadores ocupados temporária ou intermitentemente e não em caso de trabalho habitual em certo país.

Alguns tratados internacionais estabelecem que se o trabalhador presta serviços no estrangeiro em caráter temporário ou eventual, geralmente de até seis meses, é aplicável a lei da sede da empresa, caso ocorra o acidente. ${ }^{27}$

Mostra o art. 198 do Código de Bustamante que "é igualmente territorial a legislação sobre os acidentes do trabalho e a proteção social do trabalhador" Indica o referido código que a lei aplicável é a lex loci laboris ou a lei do local onde ocorreu o infortúnio.

No caso de empregados contratados no Brasil ou transferidos por empresas prestadoras de serviços de engenharia, inclusive consultoria, projetos e obras, montagens, gerenciamento e congêneres, para prestar serviços no Exterior aplica-se a Lei n. 7.064/82. Esta norma explicita no parágrafo único do art. $2^{\circ}$ que é aplicável a tais trabalhadores a lei brasileira sobre Previdência Social. Hoje essa norma é a Lei n. 8.213, que nos arts. 19 a 23 inclui regras sobre acidente do trabalho. Isso quer dizer que se aplica a nossa legislação acidentária ao empregado contratado ou transferido para o Exterior para trabalhar para empresa de engenharia, caso sofra o acidente. $\mathrm{O}$ art. 11 da Lei n. 7.064 prevê que não são devidas certas contribuições, mas não se refere ao custeio de acidente do trabalho, o que mostra que a empresa deverá recolher a contribuição de acidente do trabalho de 1,2 ou $3 \%$ sobre a folha de pagamentos.

Considera o inciso I, do art. 12 da Lei n. 8.212/91, como segurado obrigatório, na condição de empregado: 1. o brasileiro ou estrangeiro domiciliado e contratado no Brasil para trabalhar como empregado em sucursal ou agência de empresa nacional no Exterior; 2. o brasileiro civil que trabalha para a União, no Exterior, em organismos oficiais brasileiros ou internacionais dos quais o Brasil seja membro efetivo, ainda que lá domiciliado e contratado, salvo se segurado na forma 
da legislação vigente do país do domić́lio; 3. o brasileiro ou estrangeiro domiciliado e contratado no Brasil para trabalhar como empregado em empresa domiciliada no Exterior, cuja maioria do capital votante pertença a empresa brasileira de capital nacional. Nesses casos, se o acidente do trabalho ocorrer no estrangeiro, o empregado é considerado segurado da nossa Previdência Social, fazendo jus aos benefícios de acidente do trabalho previstos no Brasil pela Lei n. 8.213.

\section{Globalização}

Com a globalização tem sido verificado que há um maior número de trabalhadores que passam a trabalhar em outros países ou a circular de um país para o outro para prestar serviços.

O capital tem uma mobilidade muito grande. Fala-se que não tem pátria, pois irá para onde melhor possa obter lucros, no local em que os custos, inclusive trabalhistas, sejam menores. $\mathrm{O}$ trabalho não tem a mesma mobilidade do capital, mas tem tido mobilidade. Trabalhadores de um país passam a prestar serviços em um ou outros países.

No Mercosul, verifica-se do art. $1^{\circ}$ do referido tratado que há a livre circulação de serviços entre os países-membros. Isso implica circulação de trabalhadores e a existência de mais de uma lei trabalhista a ser aplicável. Há tentativa de harmonização dos direitos trabalhistas e não de unificação, que é impossível, dada as diferenças culturais, históricas, geográficas, etc. existentes entre seus países-membros.

Os grupos internacionais operam em vários países. Em certos casos há muitas fusões de empresas internacionais, pertencentes a países diversos. Lembre-se a recente atuação conjunta entre a Daimler Benz e a Crysler, visando melhor distribuir seus produtos no mundo. Há, portanto, uma multiplicidade dos grupos internacionais e das sociedades multinacionais, com a transformação das relações de trabalho, como assevera Michel Buy. ${ }^{28}$

Octavio Bueno Magano afirma que a lex loci executionis deve deixar de prevalecer para os grupos de empresas, pois a situação de fato mostra mais conexão com a lei do país de origem do empregado do que com a lei do local de

28. Buy, Michel. Le structure juridique de l'expatriation em le salarié expatrié, Aix-en-Provence, Presses Universitaires d'Aix-Marseille, 1990, p. 11. 
trabalho. ${ }^{29} \mathrm{O}$ contrato de trabalho não mais ficaria vinculado à lei do local de prestação dos serviços, mas à do local em que se encontre o centro de direção econômica do grupo empregador. O grupo de empresas é quem fixa a remuneração do empregado, pois a direção do grupo é que dá as regras gerais na empresa, havendo diretriz uniforme da gestão de pessoal e de como devem desenvolver o serviço, o que é feito por determinação de sua sede e não muitas vezes da filial no país da prestação dos serviços. Quem dirige o empregado é a matriz da empresa, daí porque seria aplicável a lei da matriz do grupo de empresa. A exceção seria a observância da lei trabalhista mais favorável ao trabalhador, a do local da prestação dos serviços ou do local da contratação.

Leciona Pietro Magno que "a lei aplicável ao contrato de grupo é a lei da sede. No caso de ser mudada a sede, pode mudar a lei aplicável" 30

A Convenção de Roma prevê que no caso de inexistir prestação habitual de serviços pelo trabalhador num determinado país deve ser aplicada a lei da sede da empresa. O Segundo Congresso Internacional de Direito do Trabalho, realizado em Genebra, em 1957, já havia entendido pela submissão do contrato de trabalho à lei da sede da empresa na hipótese de prestação de serviços apenas "ocasionais ou temporários em outro país ou, interinamente, nos dois territórios." 31

Em caso de trabalho ocasional, provisório, eventual, seria possível aplicar a lei do local da contratação. Exemplo seria o trabalhador prestar serviços eventualmente em outro país, mas trabalhar de forma habitual em certo país. Nesse caso, não se aplicaria a lei do local da prestação de serviços provisórios, pois estes serão eventuais, mas a do local em que os serviços são prestados com habitualidade. É o caso da aplicação da lei onde o serviço é normalmente prestado, onde o trabalhador reside com ânimo permanente.

A exceção à regra ocorreria em relação a dispositivos relativos à saúde e segurança do trabalhador, duração do trabalho, proteção do trabalho das mulheres

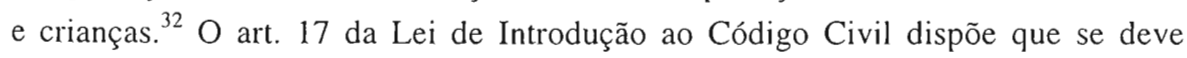

29. Magano, Octavio Bueno. Internacionalização das relações de trabalho, in Direito e Comércio Internacional: tendências e perspectivas Estudos em homenagem ao prof. Irineu Strenger, São Paulo, LTr, 1994, p. 211.

30. Magno, Pietro. Il lavoro All'Estero, Padova, Cedam, 1990, pp. 140/1.

31. Apud Süssekind, Arnaldo. Comentários à Consolidação das Leis do Trabalho e à legislação complementar, Rio de Janeiro, Freitas Bastos, 1960, v. I, pp. 46-47.

32. Buy, Michel. Le structure juridique de l'expatriation, in Le salarié expatrié, Ain-en-Provence, Presses Universitaires de D'Aix-Marseille, 1991, p. 17. 
observar a lei brasileira em se tratando de normas de ordem pública, como ocorre com as anteriormente mencionadas, pois a lei estrangeira não poderia ser aplicada em razão de ofender normas de ordem pública. A soberania do Estado em relação ao seu nacional leva à aplicação da lei do referido país e não da norma do local da prestação dos serviços, principalmente se for mais benéfica ao empregado. No âmbito internacional, Felice Morgenstern tem o mesmo entendimento de que "é universalmente admitido que o Estado do foro pode recusar a aplicação de certas disposições de uma lei estrangeira, quer tenha ela sido escolhida pelas partes quer seja aplicável por outro fundamento, se for contrária à ordem pública. ${ }^{33}$ Exemplo no Brasil seria se a legislação estrangeira permitisse que menor de dezoito anos, contratado no estrangeiro para prestar serviços em nosso território, trabalhasse em período noturno, quando o inciso XXXIII, do art. $7^{\circ}$ da Constituição, veda o trabalho noturno do menor nessa idade. Nesse caso, por força até da Constituição, teria de ser aplicada a lei brasileira e não a estrangeira.

VII. Conclusão

São vários os elementos de conexão que na prática são utilizados: lei do local da prestação dos serviços, lei do local da contratação, lei da sede da empresa, lugar da celebração do contrato, lugar de onde são emitidas as ordens de serviço, moeda utilizada para o pagamento do salário, língua na qual foi redigido o contrato, nacionalidade comum, autonomia da vontade, norma mais favorável. Em certos casos, não se aplica apenas um dos elementos de conexão, mas a combinação de vários deles, com critérios flexíveis. A observância da autonomia da vontade nem sempre pode ser utilizada, pois o empregador pode impor ao empregado a norma a ser aplicada, daí a necessidade de proteção do trabalhador. Entretanto, a aplicação da lei mais favorável é que irá trazer maiores vantagens ao empregado, fazendo, muitas vezes, a verdadeira Justiça.

São Paulo, março de 1999. 